\title{
Erratum to: Solid phase extraction of tritiated contaminants from tritium-containing waste oils
}

\author{
Andrzej Olejniczak ${ }^{1,2}$ (1) Jacek Fall $^{3} \cdot$ Katarzyna Olejniczak $^{1,2} \cdot$ Marina V. Gustova $^{2} \cdot$ \\ Alexandr G. Shostenko ${ }^{1}$
}

Published online: 6 October 2016

(C) Akadémiai Kiadó, Budapest, Hungary 2016

\section{Erratum to: J Radioanal Nucl Chem DOI 10.1007/s10967-016-4953-8}

The original article includes an error in Table 3. The correct version of the Table 3 is provided in this erratum.

The superscript and subscript terms which were not properly appeared throughout the article have been corrected in the original version.

The online version of the original article can be found under doi:10.1007/s10967-016-4953-8.

Andrzej Olejniczak

aolejnic@chem.umk.pl

1 Faculty of Chemistry, Nicolaus Copernicus University, ul. Gagarina 7, 87-100 Torun, Poland

2 Flerov Laboratory of Nuclear Reactions, Joint Institute for Nuclear Research, Joliot-Curie 6, Dubna, Russia 141980

3 Oil and Gas Institute-NRI, ul. Lubicz 25A, 31-503 Kraków, Poland 
Table 3 The main classes of compounds identified in used tritium-containing VM-5 oil

\begin{tabular}{|c|c|c|c|}
\hline Compound type & Structure & & Designation $^{\mathrm{a}}$ \\
\hline Normal alkanes & $\mathrm{C}_{n} \mathrm{H}_{2 n+2}$ & $n=8$ to 24 & $\mathrm{C} 8-\mathrm{C} 24$ \\
\hline Monomethyl and isoprenoid alkanes & & $n=0$ to 3 & $i \mathrm{C} 8-i \mathrm{C} 22$ \\
\hline Normal methyl ketones & $\mathrm{CH}_{3} \mathrm{C}(\mathrm{C}$ & $n=4$ to 20 & K6-K22 \\
\hline Isoprenoid ketones & & $n=0$ to 2 & $i \mathrm{~K} 8-i \mathrm{~K} 22$ \\
\hline Normal $\gamma$-lactones & & $n=1$ to 13 & L5-L17 \\
\hline Isoprenoid $\gamma$-lactones & & $n=0$ to 3 & MeL5-MeL22 \\
\hline Normal carboxylic acids & $\mathrm{C}_{n} \mathrm{H}_{2 n+1} \mathrm{C}$ & $n=3$ to 19 & A4-A20 \\
\hline \multicolumn{4}{|c|}{ Monomethyl and isoprenoid carboxylic acids } \\
\hline $2,6,10, \ldots$-Methylbranched & & $n=0$ to 3 & $i_{2} \mathrm{~A} 5-i_{2} \mathrm{~A} 20$ \\
\hline $3,7,11, \ldots$-Methylbranched & & $n=0$ to 3 & $i_{3} \mathrm{~A} 5-i_{3} \mathrm{~A} 21$ \\
\hline $4,8,12, \ldots$-Methylbranched & & $n=0$ to 3 & $i_{4} \mathrm{~A} 6-i_{4} \mathrm{~A} 22$ \\
\hline
\end{tabular}

a The complete list of identified isoprenoid compounds is available in Tables S1 and S2 in the Sup. Info. $x \leq y=1,2,3,5$ 